RESEARCH PAPER RP1677

Part of Journal of Research of the National Bureau of Standards, Volume 35, November 1945

\title{
EFFECT OF PRESSURE ON THE MELTING OF CRYSTALLINE RUBBER ${ }^{1}$
}

\author{
By Lawrence A. Wood, Norman Bekkedahl, and Ralph E. Gibson ${ }^{2}$
}

\section{ABSTRACT}

The effect of hydrostatic pressure on the melting of crystalline rubber has been the subject of a brief investigation extending to pressures above 1,000 atmospheres. With a particular sample of stark rubber, it was found possible to raise the temperature of melting, as determined by the disappearance of birefringence, from about $36^{\circ}$ to $70^{\circ} \mathrm{C}$ by the application of a pressure of 1,170 bars $\left(1,170 \times 10^{\circ}\right.$ dynes $\left./ \mathrm{cm}^{2}\right)$. The results, including observations at intermediate pressures, can be represented adequately by the equation $\log _{10}(p+1,300)=5.9428-(875 / T)$.

\section{CONTENTS}

I. Introduction

II. Sample

III. Apparatus and procedure

IV. Results and discussion

V. References

\section{INTRODUCTION}

The effect of hydrostatic pressure on the melting of crystalline rubber has been the subject of a brief investigation extending to pressures above 1,000 atmospheres. With a particular sample of stark rubber it was found possible to raise the temperature of melting: as determined by the disappearance of birefringence, from about $36^{\circ}$ to $70^{\circ} \mathrm{C}$ by the application of a pressure of 1,170 bars $\left(1,170 \times 10^{6}\right.$ dynes $\left(\mathrm{cm}^{2}\right)$. The results, including observations at intermediate pressures, are given in table 1 and in figure 1.

\section{SAMPLE}

The crystalline smoked-sheet sample, called stark rubber, as it had a melting range above room temperature, was furnished in 1939 by H. I. Cramer while he was a professor at the University of Akron.

Melting of a portion of this sample at atmospheric pressure was determined from observations of volume changes in a mercury-filled dilatometer by a method previously described $[1,2] .^{3}$ It can be seen from the temperature-volume relation shown in figure 2 that the melting occurred over a range of temperature from $32^{\circ}$ to $39^{\circ} \mathrm{C}$.

\footnotetext{
${ }^{1}$ Also appears in J. Chem. Phys. 13, 475 (1945).

2 At the time this work was done, Dr. Gibson was a member of the staff of the Geophysical Laboratory of the Carnegie Institution of Washington.

${ }_{3}$ Figures in brackets indicate the literature references at the end of this paper.
} 
The disappearance of the birefringence, which according to figure 1 takes place close to $36^{\circ} \mathrm{C}$ at atmospheric pressure, evidently defines a position near the center of the melting range.

The expansivity $(1 / V)(d V / d T)$ at $25^{\circ} \mathrm{C}$ of the amorphous rubber calculated from data plotted in figure 2 is found to be $650 \times 10^{-6}$ per degree centigrade and that of the crystalline rubber $590 \times 10^{-6}$ per degree centigrade.

\section{APPARATUS AND PROCEDURE}

The high-pressure equipment used in this investigation was located in the Geophysical Laboratory of the Carnegie Institution of Washington and has been described in previous papers $[3,4]$. The approximate adjustment of the pressure was made by means of a hand pump and the fine adjustment by a screw plunger operated by a wheel. The amount of pressure was determined by a calibrated manganin wire resistance-gage $[5,6]$.

Specimens of the stark rubber sample were cut into strips about a millimeter in thickness. One strip of this stark rubber, together with a similar strip previously melted by heating to about $70^{\circ} \mathrm{C}$, was placed side by side in a glass piezometer. The use of two specimens adjacent to each other permitted an excellent visual criterion for determining when birefringence disappeared.

Ethylene glycol was used as a confining liquid in the piezometer. Water was found to be unsatisfactory for this purpose as it penetrated the rubber specimens and impaired their transparency after several hours at high pressures. No such difficulty was encountered with the ethylene glycol.

Light from a 6 -volt, 32-candlepower lamp, after being polarized by a sheet of Polaroid, passed through the window of the pressure equipment and through the specimen. The polarized light was observed, after emerging from the equipment, by the use of a second sheet of Polaroid as analyzer.

In operation, the piezometer containing the specimens was placed in the apparatus, the pressure increased to about 1,300 bars, and the temperature of the bath raised to the desired value. After temperature equilibrium was attained, the pressure was slowly lowered and continuous observations made of the birefringence. Except during the melting of the stark specimen, no significant variation with pressure was noted in the appearance of the birefringence of the two specimens between crossed Polaroids.

\section{RESULTS AND DISCUSSION}

The change in birefringence associated with the melting of the stark specimen was found to take place over a small range of pressure, with the major portion of the change occurring within an interval of only a few bars. The pressure at which the change of birefringence was most rapid has been used as abscissa in figure 1 , and the corresponding bath temperature used as ordinate. A new specimen, cut from the same sheet of stark rubber, was required for each point. The data from which the curve was plotted are given in the first two columns of table 1 . 


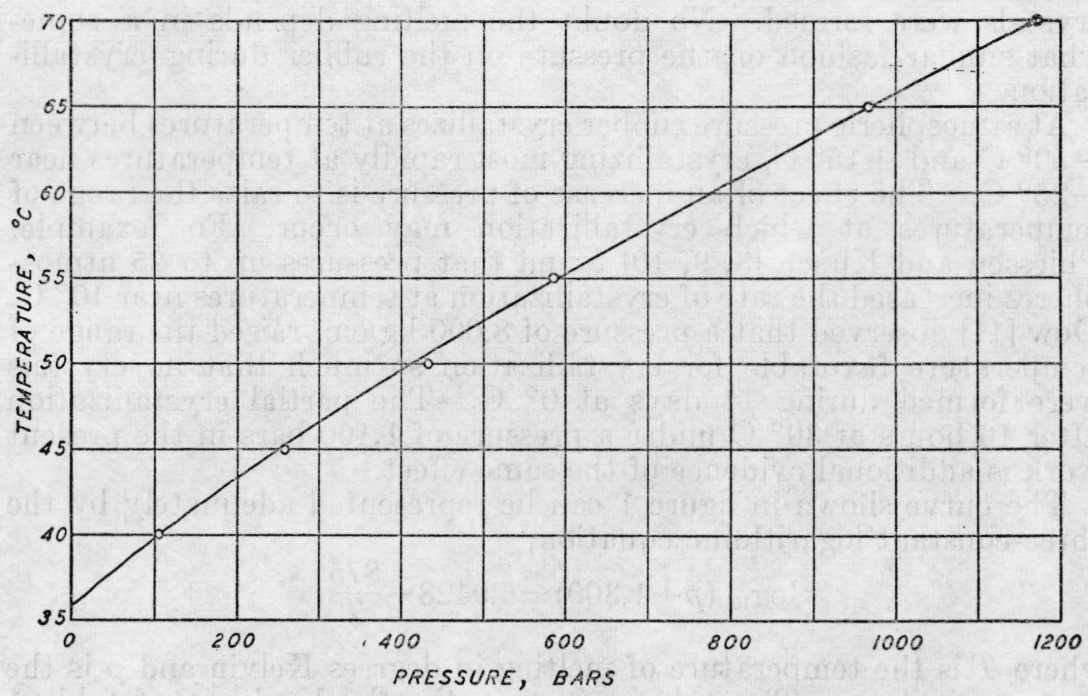

FIGURE 1.-Relation between temperature of melting and applied pressure for a sample of stark rubber.

TABLE 1.-Pressure and related quantities at temperature of melting

\begin{tabular}{|c|c|c|c|c|}
\hline \multirow{2}{*}{$\begin{array}{c}\text { Temperature of } \\
\text { melting }\end{array}$} & \multicolumn{2}{|c|}{ Pressure } & \multirow{2}{*}{$\begin{array}{l}d T / d p \\
\text { calculated }\end{array}$} & \multirow{2}{*}{$\begin{array}{l}L / \Delta V, \\
\text { calculated }\end{array}$} \\
\hline & Observed & Calculated & & \\
\hline${ }^{\circ} \mathrm{C}$ & Bars & Bars & deg C/bar & $\mathrm{j} / \mathrm{cm}^{3}{ }^{3}$ \\
\hline $\begin{array}{l}36.2 \\
40\end{array}$ & 106 & $\begin{array}{r}1 \\
108\end{array}$ & $\begin{array}{r}0.0365 \\
.0345\end{array}$ & $\begin{array}{l}846 \\
906\end{array}$ \\
\hline 45 & 259 & 258 & .0323 & 987 \\
\hline $\begin{array}{l}50 \\
55\end{array}$ & $\begin{array}{l}433 \\
586\end{array}$ & $\begin{array}{l}419 \\
590\end{array}$ & $\begin{array}{r}.0302 \\
0283\end{array}$ & $\begin{array}{l}1,060 \\
1,160\end{array}$ \\
\hline 65 & $\begin{array}{l}580 \\
967\end{array}$ & $\begin{array}{l}590 \\
966\end{array}$ & .0250 & $\begin{array}{l}1,160 \\
1,350\end{array}$ \\
\hline 70 & 1,170 & 1,172 & .0236 & 1,450 \\
\hline
\end{tabular}

The relation between the temperature of melting and the pressura shown by the curve cannot be regarded as valid for crystalline rubber having at atmospheric pressure a melting range different from that described here. As the melting range at atmospheric pressure is dependent on the temperature at which the crystals were formed [7], this fact limits the application of the present results. However, if a study were to be made of rubber crystallized at different temperatures, it is presumed that as a first approximation a family of curves not too far from parallel would be obtained with displacement along the temperature axis.

Some crystallization was observed when amorphous specimens were kept under a pressure of about 1,100 bars at $30^{\circ} \mathrm{C}$ for 16 hours. It was observed that the crystals formed in this manner melted at a much lower temperature than the value for the same pressure given by the curve in figure 1 . The crystals formed under these conditions were evidently different from those present originally in the stark rubber. At atmospheric pressure the temperature of melting, as already mentioned, is dependent on the temperature at which the 
crystals were formed. No doubt the melting depends in a somewhat similar fashion on the pressure on the rubber during crystallization.

At atmospheric pressure rubber crystallizes at temperatures between $-50^{\circ} \mathrm{C}$ and $+15^{\circ} \mathrm{C}$, crystallizing most rapidly at temperatures near $-25^{\circ} \mathrm{C}$. The effect of an increase of pressure is to raise the range of temperatures at which crystallization may occur. For example, Thiessen and Kirsch [8, 9, 10] found that pressures up to 25 atmospheres increased the rate of crystallization at temperatures near $10^{\circ} \mathrm{C}$. Dow [11] observed that a pressure of $8,000 \mathrm{~kg} / \mathrm{cm}^{2}$ raised the range of temperature favorable for crystallization so much that no crystals were formed during 14 days at $0^{\circ} \mathrm{C}$. The partial crystallization after 16 hours at $30^{\circ} \mathrm{C}$ under a pressure of 1,100 bars in the present work is additional evidence of the same effect.

The curve shown in figure 1 can be represented adequately by the three-constant logarithmic equation,

$$
\log _{10}(p+1,300)=5.9428-\frac{875}{T},
$$

where $T$ is the temperature of melting in degrees Kelvin and $p$ is the pressure in bars. The values given in the third column of table 1 are calculated from the above equation. A differentiation of the equation gives

$$
\frac{d T}{d p}=\frac{T^{2}}{2,015(p+1,300)}
$$

from which the values in the fourth column of the table were calculated.

The use of the Clapeyron equation,

$$
\frac{d p}{d T}=\frac{L}{T \Delta V}
$$

where $L$ is the heat of fusion and $\Delta V$ the corresponding change in volume, permits a calculation of $L / \Delta V$ from the data just given. This quantity, in joules per cubic centimeter of volume change, is shown in the last column of the table.

From the dilatometric measurements represented by the graph in figure $2, \Delta V$ was found to be $0.0191 \mathrm{~cm}^{3} / \mathrm{g}$ of rubber at $36.2^{\circ} \mathrm{C}$. From these data the value of $L$ for this sample is calculated to be $16.2 \mathrm{j} / \mathrm{g}$.

Other observations in this laboratory have shown that this sample of stark rubber could undergo additional crystallization at lower temperatures. The full heat of fusion should include the contribution of these additional crystals, which were observed to form at the lower temperatures. Therefore, we do not regard the value just given as the full heat of fusion of crystalline rubber at $36.2^{\circ} \mathrm{C}$. A direct measurement [12] of the heat of fusion of another sample of rubber melting over a range centered at about $11^{\circ} \mathrm{C}$ yielded $16.7 \mathrm{j} / \mathrm{g}$. The corresponding value at $36.2^{\circ} \mathrm{C}$ might be expected to be larger than that at $11^{\circ} \mathrm{C}$. The term $\Delta V$ and $T$ in the Clapeyron equation are both larger at the higher temperature, but a lack of data regarding the values of $(d p) /(d T)$ at 1 bar for samples melting between $11^{\circ}$ and $36.2^{\circ} \mathrm{C}$ prevents drawing a definite conclusion. In spite of the impossibility of making an exact calculation with the data available, the agreement in order of magnitude is quite satisfactory. 
The rate of change of melting temperature with pressure is observed to have the value of 0.037 degree centigrade per bar at the lowest pressures and to decrease with increasing pressure to a value of about 0.024 degree centigrade per bar at 1,170 bars. The average value over the range studied is 0.029 degree centigrade per bar. This is considerably lower than the average value calculated from a single observation of Dow [11], who found rubber crystallized at $0^{\circ} \mathrm{C}$ to melt at $77.5^{\circ} \mathrm{C}$ under a pressure of $1,270 \mathrm{~kg} / \mathrm{cm}^{2}$. From this observation one may calculate a value of 0.052 degree centigrade per bar if $11^{\circ} \mathrm{C}$ is taken as the melting temperature at atmospheric pressure for rubber crystallized at $0^{\circ} \mathrm{C}[1]$.

The experimental observations for the present investigation were made in the summer of 1940 , but earlier publication was prevented by war activities, which also led to the abandonment of a more extensive investigation that had been planned.

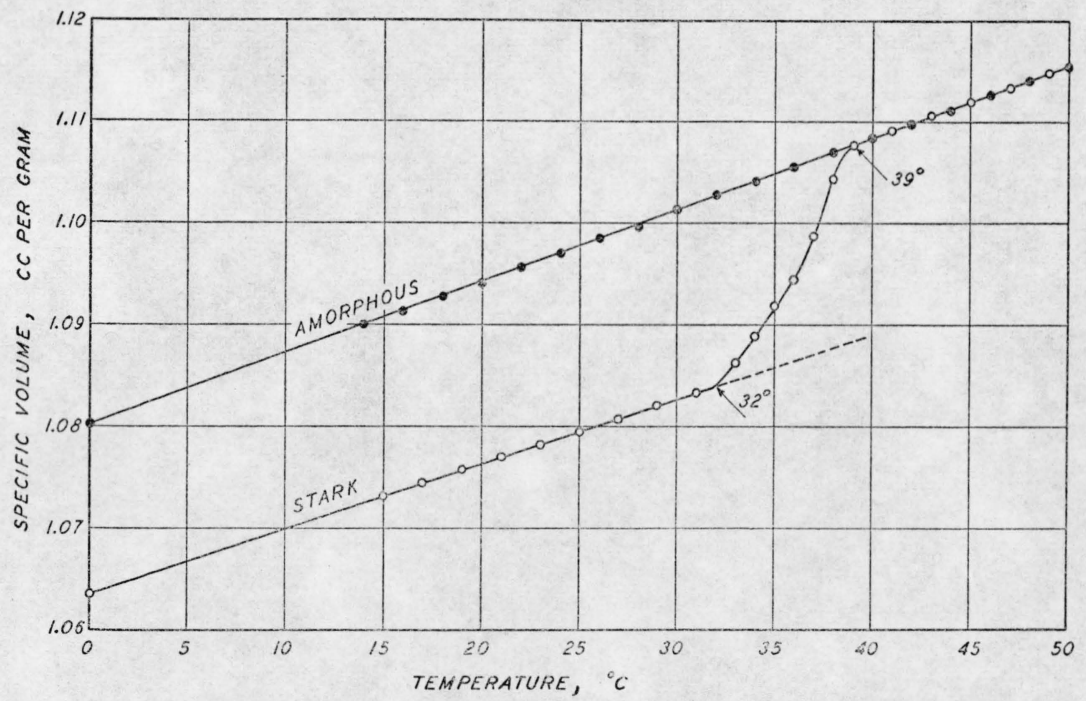

FIGURE 2.-Relation between specific volume and temperature at atmospheric pressure for the sample of stark rubber, before and after melting.

\section{REFERENCES}

[1] N. Bekkedahl, Forms of rubber as indicated by temperature-volume relationship, J. Research NBS 13, 411 (1934) RP717; reprinted in Rubber Chem. Tech. 8, 5 (1935).

[2] N. Bekkedahl and L. A. Wood, Crystallization of vulcanized rubber, Ind. Eng. Chem. 33, 381 (1941); Rubber Chem. Tech. 14, 347 (1941).

[3] R. E. Gibson and John F. Kincaid, The influence of temperature and pressure on the volume and refractive index of benzene, J. Am. Chem. Soc. 60, 511 (1938).

[4] R. E. Gibson, The compressions of solutions of certain salts in water, glycol, and methanol, J. Am. Chem. Soc. 59, 1521 (1937).

[5] R. E. Gibson, The influence of concentration on the compressions of aqueous solutions of certain sulfates, J. Am. Chem. Soc. 56, 4 (1934).

[6] R. E. Gibson, The influence of the concentration and nature of the solute on the compressions of certain aqueous solutions, J. Am. Chem. Soc. 5\%, 284 (1935).

[7] N. Bekkedahl and L. A. Wood, Influence of the temperature of crystallization on the melting of crystalline rubber, J. Chem. Phys. 9, 193 (1941); Rubber Chem. Tech. 14, 544 (1941). 
[8] P. A. Thiessen and W. Kirsch, Crystallization of rubber by pressure, Naturwissenschaften 26, 387 (1938); translated in Rubber Chem. Tech. 12, 12 (1939).

[9] P. A. Thiessen and W. Kirsch, Crystallization of weakly vulcanized rubber by pressure, Naturwissenschaften 2\%, 390 (1939); translated in Rubber Chem. Tech. 13, 48 (1940).

[10] W. Kirsch, Equilibria between crystals and melts in rubber and their dependency on temperature and pressure, Dissertation (Trillsch \& Huther, Berlin, 1937).

[11] R. B. Dow, Inhibition of crystallization of rubber by high pressure, J. Chem. Phys. 7, 201 (1939); Rubber Chem. Tech. 12, 496 (1939).

[12] N. Bekkedahl and $\mathrm{H}$. Matheson, Heat capacity, entropy, and free energy of rubber hydrocarbon, J. Research NBS 15, 503 (1935) RP844; Rubber Chem. Tech. 9, 264 (1936).

Washington, May 3, 1945. 